\title{
Premature singleton versus a twin or triplet infant death: parental adjustment studied through a personal interview
}

\author{
Dvorah Netzer and Ilan Arad \\ Department of Neonatology, Hadassah University Hospital, Jerusalem, Israel
}

\begin{abstract}
Parental adjustment following the death of a premature singleton or multiple birth infant has hitherto been studied by mailed questionnaires or telephone survey. In the present study, using an in-depth personal interview, grief reactions and adjustment patterns of nine families who lost a singleton premature infant ('Single Group') were compared with those of nine families who lost one of a premature multiple birth cohort ('Multiple Group'). The interview was conducted 1-4 years after the death of the infant and evaluated specific areas or 'scales' of life adjustment, including individual feelings, relationship between husband and wife, and functioning at home and at work. There was no significant difference between the paternal and maternal level of adjustment of the two groups in any of the studied scales. A positive correlation was found between maternal and paternal grief reaction of the same family in the scal es of individual feelings $(r=0.65)$, relationships between husband and wife $(r=0.70)$, and functioning at home $(r=0.57)$. Comparing the father's scale with the mother's scale revealed a significant difference only in the area of 'individual feelings'. The gestational age, maternal bonding during hospitalisation of the infant and the parental attendance at the event of death were significantly associated with the process of parental adjustment. The results of this study support previous reports of similar parental reactions following the demise of a premature singleton or multiple birth infant. Since societal environment may not recognise the need for consolation of these families, care, compassion, and sensitivity should be encouraged in dealing with these parents at the time of their infant' death, and for a long time thereafter.
\end{abstract}

Keywords: preterm death, singleton, twin, parental adjustment

\section{Introduction}

Neonatal loss is a very traumatic event for the family involved, and its psychological implications have become the subject of expanding research. ${ }^{1-14}$ Some evidence has been presented indicating that the longer the antenatal or postnatal bonding period with the infant, the deeper and more persistent are the grief reactions experienced by the parents. ${ }^{1,3,5,6,11,15}$ Father and mother apparently do not grieve uniformly. $5,6,9,12,13,16-26$

Most studies of infant death refer to mixed populations: miscarriage, still birth, neonatal death and SIDS. $3.5,12,13,16-18,20,21,23,25$ The growing number of multiple gestation deliveries resulting from hormonal therapy and in vitro fertilisation has led also to an increasing occurrence of a neonatal multiple birth death in the premature nurseries. ${ }^{6,27-30}$ In these turbulent situations, parents must endure feelings of grief and pain for their dead infant, together with ongoing care and attachment to their living child or children. Their involvement with the other babies

Correspondence: Ilan Arad MD, Department of Neonatology, Hadassah University Hospital, Mount Scopus, Jerusal em 91240, Israel. Fax: 97225823515

Received 3 December 1998; revised 29 July 1999; accepted 9 August 1999 has been assumed to ease the pain, delay the resolution of grief, or both. ${ }^{4,7,18-20,28,31}$

Only a few studies have compared the grief reactions and adjustment process of parents of a dead twin to those of bereaved singleton families. ${ }^{4,7,11,19}$ No significant difference was found between the reactions of twin vs singleton parents. The information reported in these studies was obtained through mailed questionnaires or by telephone survey. The lack of in-depth interviews, suitable for the discussion of particular details of individual parents' situation, has recently been mentioned. ${ }^{32}$

We decided to study and compare the adjustment process of parents following the demise of a premature singleton infant with those who lost one of twins or triplets, using a personal interview, and to evaluate the impact of perinatal events surrounding the death of the infant.

\section{Patients and methods}

During the years 1990-1993, 630 newborn infants were treated in the Neonatal Intensive Care Unit (NICU) at the Mount Scopus Hadassah University 
Hospital, 441 of them prematurely born. During this period 71 premature infants died.

Thirty-six families whose infant survived more than 3 days, were considered candidates for inclusion in the study. Six non-Jewish families were excluded from the study in order to diminish cultural and language variability effect, and four Jewish families were not located. Thus, a total of 26 Jewish families were approached, including 16 couples who gave birth to a singleton infant, and 10 couples who were parents of twins or triplets. Families who refused to be interviewed consisted of seven singleton families and one multiple birth family. All of them expressed fear of emotional difficulties in facing further confrontation with their memories of the event. They were comparable by age and socio-economic status with the participating families. The remaining 18 families were interviewed: nine families who were parents of singleborn infants who died, comprised the 'Single Group', whereas nine families of multiple-birth infants comprised the 'Multiple Group'. The latter group included four families of twins with one survivor, three triplet families with one survivor, and two triplet families with two survivors.

The couples were interviewed together, at their homes, by the social worker (DN) whom they had known since the hospitalisation of their newborn infants in the NICU. The interview occurred between one and four years after their infant's death, and lasted $1 \frac{1}{2}-3$ hours. The interview was conducted using a questionnaire based upon el ements used in other studies ${ }^{1,9,16,17,33}$ rel ating to five specific areas or 'scal es' of life adjustment:

1 Individual feelings Questions relating to parents looking at photographs of the baby, speaking about him, having sleep problems, often thinking of the infant, imagining him, feeling jealous of others' infants, having psychosomatic problems (eight items).

2 Relationship between husband and wife Questions relating to parental talking about the dead infant, feelings of anger, lack of patience, lack or excess of concern for the spouse, discussion of marital difficulties, sexual relations and recreational patterns (seven items).

3 Social relations Questions relating to family relations, talking with friends about the dead infant, going out with friends and inviting them home (five items).

4 Functioning at home Questions relating to feelings about the home environment, the ability to perform and concentrate on household duties (three items).
5 Functioning at work Questions relating to the return to work, ability to concentrate at work, and pattern of performance (four items).

In each scale we coded three degrees of adjustment, using the numbers one, two and three. The lower number denotes quicker adjustment and return to the former life pattern, whereas the higher number denotes interference or trouble in adjustment. For instance, if someone had no sleeping problems he was given the number one. If he still had trouble falling asleep or had frequent nightmares, he was given the number three. Number two meant that he had few sleep disturbances. The average score of an individual parent in each scale was calculated, and parental reactions of the two groups were compared as were maternal and paternal patterns within each group.

Parental reactions and their attitude during the hospitalisation of their infant in the NICU were evaluated according to the social worker's records from that period. Perinatal and socio-demographic data were obtained from the medical files and were confirmed during the interview.

The Mann-Whitney and the $\chi^{2}$ test were used for comparisons between and within the study groups. The level of significance was taken to be $\mathrm{P}<0.05$. To compare and measure associations between mothers' and fathers' scales, Wilcoxon Matched-Pairs Test and the Kendell Correlation Coefficient were used.

\section{Results}

To find the internal consistency of the five scales, Cronbach's Alpha was computed. For the first scale (individual feelings) al pha was 0.79 for the mothers and 0.83 for the fathers. The alpha values for the second scale (relationship between husband and wife) after excluding one item relating to feeling jeal ous of another's infant, were 0.71 and 0.66 for the mothers and fathers, respectively. The third scale (social relations) showed very little consistency and was excluded from further analysis. In the fourth scale (functioning at home) one item, relating to ability to concentrate, was excluded and the alpha was 0.83 for the mothers and 0.94 for the fathers. One item, relating to the return to a regular work schedule was excluded from the fifth scale (functioning at work) as well, and the al pha values were 0.76 and 0.69 for the mothers and fathers, respectively. The items were removed from the scales in order to increase their internal consistency.

The perinatal and socio-demographic variables of the two groups are presented in Table1. Notably, parents of the 'Single Group' were older than those of the 'Multiple Group' and with more previously 
Table 1 Characteristics of the study groups

\begin{tabular}{|c|c|c|c|}
\hline & $\begin{array}{l}\text { Single } \\
\text { group }(n=9)\end{array}$ & $\begin{array}{l}\text { Multiple } \\
\text { group }(n=9)\end{array}$ & $\begin{array}{l}P \\
\text { value }\end{array}$ \\
\hline Birth weight (grams) ${ }^{a}$ & $1123 \pm 646$ & $978 \pm 226$ & NS \\
\hline Gestational age (weeks) ${ }^{a}$ & $28.1 \pm 3.8$ & $28.8 \pm 2.5$ & NS \\
\hline Outborn & 6 & 6 & NS \\
\hline Femal es & 2 & 1 & NS \\
\hline Caesarean section & 2 & 7 & 0.018 \\
\hline Maternal age (years) ${ }^{a}$ & $31.8 \pm 5.0$ & $24.9 \pm 2.6$ & 0.005 \\
\hline Paternal age (years) ${ }^{a}$ & $35.9 \pm 6.9$ & $27.6 \pm 2.6$ & 0.015 \\
\hline Death age (days) ${ }^{\mathrm{a}}$ & $56.7 \pm 73.5$ & $13.7 \pm 14.7$ & NS \\
\hline Post loss period (months) ${ }^{a}$ & $29.2 \pm 12.2$ & $26.2 \pm 14.3$ & NS \\
\hline Mother present at death & 4 & 0 & 0.023 \\
\hline Father present at death & 4 & 0 & 0.023 \\
\hline Parent present at burial & 4 & 1 & NS \\
\hline Good maternal bonding & 7 & 4 & NS \\
\hline Good paternal bonding & 9 & 7 & NS \\
\hline Preparation for death & 7 & 8 & NS \\
\hline Previous siblings per family & 2.9 & 0.3 & 0.004 \\
\hline New siblings per family & 0.7 & 0.4 & NS \\
\hline Maternal school years $>12$ & 4 & 5 & NS \\
\hline SES ${ }^{b}$ above average & 5 & 2 & NS \\
\hline Orthodox family & 4 & 3 & NS \\
\hline
\end{tabular}

avalues are mean \pm standard deviation; ${ }^{\text {b}}$ SES: Socio-economic status

Table 2 Levels of adjustment ${ }^{\mathrm{a}}$

\begin{tabular}{|c|c|c|c|}
\hline Scales & $\begin{array}{l}\text { Single } \\
\text { group }(n=9)\end{array}$ & $\begin{array}{l}\text { Multiple } \\
\text { group }(n=9)\end{array}$ & $\begin{array}{l}P \\
\text { value }\end{array}$ \\
\hline \multicolumn{4}{|c|}{1 Individual feelings } \\
\hline Mother & $1.71 \pm 0.53$ & $1.65 \pm 0.51$ & NS \\
\hline Father & $1.57 \pm 0.44$ & $1.40 \pm 0.47$ & NS \\
\hline \multicolumn{4}{|c|}{2 Relations between parents } \\
\hline Mother & $1.39 \pm 0.31$ & $1.30 \pm 0.30$ & NS \\
\hline Father & $1.37 \pm 0.36$ & $1.28 \pm 0.30$ & NS \\
\hline \multicolumn{4}{|c|}{4 Function at home } \\
\hline Mother & $1.33 \pm 0.50$ & $1.39 \pm 0.49$ & NS \\
\hline Father & $1.22 \pm 0.36$ & $1.22 \pm 0.44$ & NS \\
\hline \multicolumn{4}{|c|}{5 Function at work } \\
\hline Mother & $1.54 \pm 0.59$ & $1.07 \pm 0.15$ & NS \\
\hline Father & $1.19 \pm 0.34$ & $1.15 \pm 0.24$ & NS \\
\hline
\end{tabular}

aalues are mean \pm standard deviation

delivered children per family. Also, about half of them attended the death of their baby, compared with none of the 'Multiple Group' parents. As expected, Caesarean section was performed more frequently in the 'Multiple Group'.

The level of parental adjustment in the remaining four scales of the two study groups is presented in Table2. There was no significant difference between the maternal and paternal level of adjustment of the two groups in any of the four scales. A positive correlation was found between maternal and paternal reactions in the same family in scal es $1(r=0.65$, $P=0.001), 2(r=0.70, P=0.001)$ and $4(r=0.57$, $P=0.013)$. Therefore, familial adjustment $w$ as al so analysed. However, no difference between the groups was evident. There was also no difference between the groups when parental adjustment over all the scales was compared (Multivariate Analysis of Variance).

Comparing the fathers' scale with the mothers' scale revealed a significant difference only in the first scale of individual feelings $(P=0.026$, Wilcoxon Matched-Pairs Test). Mothers grieved Ionger and found it more difficult to return to their previous routine, whilst fathers slept better and thought less about their dead infant.

An evaluation was also made of the impact of perinatal and socio-demographic variables on parental adjustment as measured in scales 1 and 2. There was no significant association between mode of delivery, religious belief, socio-economic status, age at death, parental presence at the burial, presence of previous siblings or the birth of new siblings, and the levels of adjustment in the two scales.

The gestational age, maternal bonding during hospitalisation and the parental attendance at the death were significantly associated with the process of parental adjustment. There was a significant difference for mothers in scale 1 by gestational age, with mothers experiencing greater difficulties in emotional adjustment following their infant's death the longer the gestational period. The mean score was 1.38 for mothers to infants with a gestational age between 25-27weeks, and 1.58 for mothers to infants with a gestational age of 28-35 weeks ( $P=0.044$, Mann-Whitney test).

Bonding was graded by the frequency of parental visits, physical contact with the infant and affectionate behaviour. The degree of maternal bonding (strong, moderate or lacking) during the hospitalisation period was significantly associated with scale 1 paternal reaction $(P=0.03)$, the mean scores being $1.81,1.63$, and 1.16 respectively. A lesser association was found with scale 1 maternal reaction $(P=0.071)$, the mean scores being $2.00,1.78$, and 1.40 respectively. No significant association was found between the degree of paternal bonding and scale 1 parental reactions or between parental bonding and scale 2 parental reactions.

Paternal presence at the time of death was weakly associated with paternal reaction in scale 1 $(P=0.086)$ and significantly associated with paternal $(P=0.011)$ and maternal $(P=0.016)$ reactions in scale2. Maternal presence at death was associated with maternal reaction $(P=0.05)$ and paternal reaction $(P=0.037)$ in scale 2 but not in scale 1 .

\section{Individual responses}

Most parents reported that the period immediately after their infant's demise was the most difficult for them but that there was an improvement with time. 
At the beginning there was crying, constantly thinking and speaking about the infant and looking at photographs.

During the adjustment process the role of a sibling often emerged in both groups. Whilst parents in the 'Single Group' referred to older siblings, parents in the 'Multiple Group' referred to the surviving sibling(s) as aiding them to overcome their grief: 'The proximity of the other children helped us not sink into despair', 'it is difficult to imagine life without her (the older daughter) after the baby died' ('Single Group' parents). 'People who do not have another baby think about the one who died. We are comforted with the survivors.' 'The surviving baby gave me strength to get up in the morning, get dressed, put on make-up, and go out.' ('Multiple Group' parents).

However, some parents said that there was no way to fill the void left by the death of the infant and thus the consoling role of the siblings at home or those who survived was incomplete: 'I feel empty even though we have an older child at home.' Or 'It is cruel of people to console us by saying that we still have a baby who survived.'

The impact of the traumatic events experienced in the NICU was often referred to by parents who expressed feelings of anxiety and fear about what may or might have happened to their living children: 'The dead baby was constantly everywhere.' 'During the first six months I was afraid that the twin would die, too.' Although the fear of impending death of the surviving infant was more characteristic of the 'Multiple Group' parents, similar concern was felt by some 'Single Group' parents who began often to check on their older sleeping children, or felt that they had to be watched more carefully. Severe disability in the future, had the infant survived despite a major brain insult, was perceived by some parents to be worse than death. Some felt that in the long term death was a blessing in disguise 'since the older children are healthy, and it would be lifelong trouble had there been a disabled child at home'. 'Multiple Group' parents also expressed fear of disability. 'The unknown future of my other two infants was more frightening than the feeling that they may die.'

Marital relationships underwent difficult times and also demanded adjustment. A few couples reported lack of patience, mutual blaming for what had occurred, some estrangement, a need for silence and a need for help from close relatives. Others said that the presence of open communication between them prior to the infant's death affected their relationship afterwards but described a change in its quality: 'We speak more than before.' 'My husband is more sensitive.' Mutual sensitivity was important for the adjustment healing process: 'At first my husband was distant, and I respected his not wanting to speak, knowing that it was temporary.' A husband who perceived his wife as a stranger after their loss was able to come closer than ever before when they began talking about the baby. Many of the couples stated, without being asked, that they were more united than before the infant's death, and were content with the closer relationship which they developed.

Functioning at home at first was 'as through a fog'. 'I did things automatically.' It changed later. A 'Multiple Group' mother felt hel pless for a long time. 'It took almost a year before I could concentrate on housework. Everything was negl ected.' Another parent said: 'I decided to change my image. I went out, bought new clothes and returned to work.' Some perceived work as an escape until inner resources were used for adjustment: 'At first I worked nights too. Now I have calmed down.' 'For six months I worked more until I understood that I had pushed everything aside. I cut down on working hours, the grief opened and I dealt with it.'

Parents from both groups complained that society prefers to relate only to a living child and, therefore, does not adequately support parents who have lost their baby. 'People think that a premature infant... is not a human being when he dies.' 'Friends feel uncomfortable and do not initiate talking about him...they do not phone. We feel that we have to help them talk.' A father of two survivors of a triplet cohort did not tell anyone that there had been three 'since no one could understand the loss.' Some parents reported that only people who had undergone similar experiences were able to speak with them openly of the loss. Many parents felt abandoned and lonely, needing support by friends and family, but 'only the hospital staff knew my baby as a person. Others knew him only from photographs and stories.' 'Friends began telling me of their losses. I didn't want to hear. I wanted them to listen to me. I wanted to talk. The people around me didn't understand.'

The responses described here demonstrate the wide range of parental experiences and feelings after the death of their infant and various patterns of adjustment to the new reality.

\section{Discussion}

In the present study higher numbers in the scores of adjustment, apparently indicating a slower and more difficult return to previous life patterns, were demonstrated in the 'Single Group' parents in three of the four scal es studied (individual feelings, relationship between husband and wife, functioning at home). However, the difference between the two study 
groups, whether scales were analysed together or separately, was not statistically significant. These results support previous reports of similar parental grief reactions and adjustment patterns following the death of a premature singleton or twin infant. $4,11,17,32$

Our 'Multiple Group' was not homogeneous, since it was composed both of twin and of triplet families with one or two surviving infants. The small number of families precluded the subdivision of the group into smaller units. Furthermore, since the basic emotional conflict between mourning at the death of a sibling and the need to care for the survivor(s) was shared by all the 'Multiple Group' families, their inclusion in one group was felt to be justifiable.

Despite similarities in adjustment some differences between the two groups did exist. 'Multiple Group' parents were younger and witnessed the death of their infant at an earlier age (although with no significant statistical difference), allowing for a shorter period of bonding. This, together with their need to direct their energy towards the surviving infant(s) could, at least partially, explain their absence at the time of death. They al so continued to care for their surviving infant(s) in the nursery for a considerable period and received the attention and understanding of the NICU personnel during the initial phase of mourning. The continuation of care and the continual exposure to the nursery personnel during hospitalisation and later on, at the follow-up clinic, might have increased the ability of the 'Multiple Group' parents to express feelings openly and enhanced their communication with the environment. This is supported by their increased willingness to participate in the study. In contrast, the 'Single Group' parents underwent a relatively abrupt separation from the NICU and its staff, except for several telephone conversations and home visits by the social worker following the infant's death. In the 'Single Group' $44 \%$ of the parents, versus $10 \%$ of the 'Multiple Group' parents refrained from participation in the study. In most cases parents explained their objections by the wish to avoid the pain associated with renewed recollection of the experience. It has been suggested that parents who refuse to disclose their feelings may be going through a more difficult process of adjustment and grief resolution than those who more willingly share their emotions. ${ }^{5,16,17,19,32}$ In such circumstances al ternate avenues of communication initiated by close family members, friends and community personnel may prove helpful.

Several studies have indicated that society does not regard the demise of a premature infant as severe a loss as that of an older infant or child. ${ }^{1,10,11}$ Furthermore, and especially valid for our study, is that fact that the Jewish tradition does not recognise the death of a newborn infant as a normal death. ${ }^{34}$ Burial is not usually attended by the parents and mourning practices are generally not exercised. Only five (four 'Single Group' and one 'Multiple Group') of the 18 families participating in the present study were present at the burial of their infant(s). Since there is little encouragement to parents from friends and family to express their feelings, parents are frequently left alone, with only each other as an outlet for the expression of grief. We suggest that the correlation between maternal and paternal reactions in three of the four scales of adjustment probably reflects this situation.

It was noted during the interviews that some ultraorthodox families tried to find consolation in attributing meanings for the events of premature birth and death. Parents said that they had the privilege of giving birth to a righteous soul who came to earth for a 'tikun' ('correction' in Hebrew) and that through them the soul found its peace. 'The baby fulfilled his role ('tikun') and that's it. Forget it all.' Yet, the cognitive explanation did not necessarily appease the emotions surrounding the death of the baby, as was evident during the interviews with the families.

The in-depth personal interview is a suitable tool for discussing particular details with grieving parents, but its use is usually limited to a small number of families, as was the case in our study. The interview occurred 1 to 4 years following the death of a premature infant. The intensity of grief and pattern of adjustment often change with time, and thus the comparison between responses recorded at the early stage of mourning may differ from those given at a later stage. However, Dyregrove and Matthiesen ${ }^{5,16,17}$ who studied families over a similar period of time found that the variability in time span has only a minor influence on parental reaction. We did not control for this variable, but since all families were interviewed at least one year after the death, which granted them some capability of perspective, and since the average post-loss period was similar in both groups (Table 1), comparison between the two groups was considered appropriate.

It should be kept in mind that the birth of a premature infant does not necessarily bring joy to the parents, but often causes anxiety, which they have to endure over a long period of time. The death of a sibling of a multiple birth cohort may accentuate the fear of a subsequent death in the siblings, precluding feelings of gratification in the presence of the surviving sibling(s).

Although the process of adjustment of the two study groups is not identical, and bearing in mind that the extent of dissimilarity may have been al tered by the small sample size, our resul ts demonstrate the comparable emotional and societal difficulties and 
complexities shared by both groups of parents. Since society in general may not recognise the need for consolation of multiple birth families, care, compassion, and sensitivity should be encouraged in supporting these parents at the time of their infant's death and for a long time thereafter.

\section{References}

1 Kennell $\boldsymbol{H}$, Slyter $\mathrm{H}$, Klaus $\mathrm{MH}$ : The mourning response of parents to the death of a newborn infant. N Engl J Med 1970; 238: 344-349.

2 Rowe J, Clyman R, Green C, Mikkelsen C, Haight J, Ataide A: Follow-up of families who experience a perinatal death. Pediatrics 1978; 62: 166-170.

3 Kennell $\mathrm{H}$, Klaus $\mathrm{MH}$ : Caring for parents of a stillborn or an infant who dies. In: Klaus MH, Kennell JH, (eds). Parent-Infant Bonding. CV Mosby Co: St. Louis, 1982, pp 259-292.

4 Wilson AL, Fenton LJ, Stevens DC, Soule DJ. The death of a newborn twin: an analysis of parental bereavement. Pediatrics 1982; 70: 587-591.

5 Dyregrov A, Matthiesen SB: Stillbirth, neonatal death and sudden infant death (SIDS): parental reactions. Scand J Psychol 1987; 28: 104-114.

6 Stierman ED: Emotional aspects of perinatal death. Clin Obstet Gynecol 1987; 30: 352-361.

7 Lewis E, Bryan EM: Management of perinatal loss of a twin. BMJ 1988; 297: 1321-1323.

8 Leon G: When a Baby Dies, Psychotherapy for Pregnancy and Newborn Loss. Yale University Press: New York, 1990.

9 Gilbert KR, Smart LS: Coping with infant or fetal loss, the couple's healing process. Brunner/Mazel Publishers: New York, 1992.

10 Covington SN, Theut SK: Reactions to perinatal loss. A qualitative analysis of the national maternal and infant health survey. Am J Orthopsychiatry 1993; 63: 215-222.

11 Harrigan R, Naber MM, Jensen KA, Tse A, Perez D: Perinatal grief: response to the loss of an infant. Neonatal Network 1993; 12: 25-31.

12 Vance JC, Najman BA, Thearle MJ, Embelton G, Foster WJ, Boyle FM: Psychological changes in parents eight months after the loss of an infant from stillbirth, neonatal death, or sudden infant death syndrome - a longitudinal study. Pediatrics 1995; 96: 933-938

13 Vance JC, Boyle FM, Najman JM, Thearle MJ. Gender differences in parental psychological distress following perinatal death or sudden infant death syndrome. Br JPsychiatry 1995; 167: 806-811.

14 Thomas V, Striegel P: Stress and grief of a perinatal loss: integrating qualitative and quantitative methods. Omega 1994-1995; 30: 299-311.
15 Goldbach KRC, Dunn DS, Toedter LJ, Lasker $\mathbf{N}$ : The effects of gestational age and gender on grief after pregnancy loss. Am J Orthopsychiatry 1991; 61: 461-467.

16 Dyregrov A, Matthiesen SB: Similarities and differences in mothers' and fathers' grief following the death of an infant. Scand J Psychol 1987; 28: 1-15.

17 Dyregrov A, Matthiesen SB: Anxiety and vulnerability in parents following the death of an infant. Scand JPsychol 1987; 28: $16-25$.

18 Davis A: Management of perinatal loss of a twin [letter]. BMJ 1988; 297: 1613

19 Lewis E, Bryan E: Management of perinatal loss of a twin. BMJ 1989; 208: 184.

20 Feeley N, Gottlieb LN: Parent's coping and communication following their infant's death. Omega 1988-1989; 19: 51-67.

21 Bohannon R: Grief responses of spouses following the death of a child: A longitudinal study. Omega 1990-1991; 22: 109-121.

22 Page-Lieberman J, Hughes CB: How fathers perceive perinatal death. MCN 1990; 15: 320-323.

23 Zeanah CH, Danis B, Hirshberg L, Dietz L: Initial adaptation in mothers and fathers following perinatal loss. Inf Mental Health J 1995; 16: 80-93.

24 Gottlieb LN, Lang A, Amsel R: The long-term effects of grief on marital intimacy following an infant's death. Omega 1996; 33: $1-19$.

25 Smart LS: The marital helping relationship following pregnancy loss and infant death. J Fam Issues 1992; 13: 81-98.

26 Wilson AL, Witzke D, Fenton LJ, Soule D: Parental response to perinatal death, mother-father differences. Am J Dis Child 1985; 139: 1235-1238.

27 Botting BJ, Macfarlane AJ, Price FV: Three, Four and More, a Study of Triplet and Higher Order Births. HMSO: London, 1990.

28 Dollfus C, Patetta M, Siegel E, Cross AW: Infant mortality: A practical approach to the analysis of the leading causes of death and risk factors. Pediatrics 1990; 86: 176-183.

29 Bryan EM: The death of a twin. Palliative Med 1995; 9: 187-192.

30 Dunn A, Macfarlane A: Recent trends in the incidence of multiple births and associated mortality in England and Wal es. Arch Dis Child 1996; 75: F10-F19.

31 Johannsen L: As birth and death coincide. MCN 1989; 14 : 89-92.

32 Cuisinier M, de Kleine M, Kollee L, Bethlehem G, de Graauw C: Grief following the loss of a newborn twin compared to a singleton. Acta Paediatr 1996; 85: 339-343.

33 Toedter LJ, Lasker $\mathbf{N}$, Alhadeff $\mathbf{M}$ : The perinatal grief scale: development and initial validation. Am J Orthopsychiatry 1988; 58: 435-449.

34 Wilonsky A, Silberstein J. Halachic responsa: problems in the neonatal intensive care unit [in Hebrew] Assia 1984; 38: 30-39. 